\title{
Real problems and countermeasures of the Food Safety News Reports
}

\author{
Jiang Ke \\ School of Public Management, Yunnan University of Finance and Economics, Kunming, \\ P.R. China \\ ( E-mail: 1341824069@qq.com )
}

\begin{abstract}
The news reports show the reality of the current food security situation, which can cause public concern about food safety. Through the 2004-2011 food safety reports, it is easy to see that the problem is to achieve food safety. Food safety, not only the complexity of its content, but also reflects that the news caused a lot of problems in society. Therefore, it is necessary to clarify the real scientific reports on food safety, and improve public awareness towards food safety incidents.
\end{abstract}

Keywords: Food safety; News; Public rationality; Industry norms.

\section{Introduction}

Food safety is closely connected with the people's health and life safety. It is an important factor for the development of economic and social stability, and it is also a concrete manifestation of the government's ability to govern. However, China's food safety regulatory events occur frequently and they are increasing year by year .In this context, I will talk about the panic produced by the food safety problem, pose questions about the government food safety regulatory functions, affecting the normal market order.

\section{2. the Problem of Food Security Im- plementation}

To study the food safety supervision and coordination dilemma we must first understand the basic concept and content of Food Safety. However, consumers, academia and relevant government departments for food safety are not having a consistent and unified view, lead to different participating subjects in the food safety objectives to generate different understandings.

Therefore, analyzing the basic meaning of "food security" is to help to understand the problem of food safety regulation, including food safety regulatory limitations, blurb, and dynamic characteristics related to all participants.

\section{1. the Dynamics of Food Safety}

Food safety is a relative concept, the concept of change by the social-economic impact, experienced a longer period of continuous development, the main gone through several stages.

(1) The number of security shift from the quality and safety;

(2) Shift from the quality and safety of food hygiene;

(3)shift from food hygiene and food safety .In 1974, the UN Food and Agriculture (FAO) in the " International Undertaking on World Food Security " was first proposed the quantity of food safety (Food Security), pointed out that the number of 
food should meet the basic needs of everybody which emphasize the " eat ." Then, in 1985, China had published the " Republic of China Food Sanitation Law" (hereinafter referred to as the Food Sanitation Law) which provides that: "Food should be non-toxic, harmless, conform to nutritional requirements, with a corresponding color, smell, taste, etc. sensory traits ", although clear the importance of food, mainly food Hygiene (food hygiene) concept have great relevance with the heads of health food department. In 2009, another act had been published - the " Food Safety Law " (hereinafter referred to as the Food Safety Law) it provides that: "Food security means food non-toxic, harmless, conform to the nutritional requirements of human health, does not cause any acute, sub- acute or chronic hazard " to get the highly requirements of food safety (Food Safety), the food is not only just " eat ", but also with nutrition which makes man healthy, it requests the food safety supervision to do more.

\section{2. the Limitations of Food Safety}

To understand the importance of food safety, public property has its special meanings to regulators. Through the food safety supervision to achieve regulatory objectives, government regulators responsible for one of the objectives of the adoption of different administrative regulations, the implementation of standards and policies of the "food security" understanding this concept is sure to have differences. Produced for government agencies bureaucratic form of organization decided to overcome coordination problems, which gives the government proposed regulatory functions to achieve practical difficulties.

\section{3. the Fuzziness of Food Safety}

Food not only with quality, health, nutrition, safety and other attributes, but also the food safety regulatory objectives should be achieved. Both of these goals have one thing in common, to meet the needs of people which had been premised, to minimize adverse effects. However, there still exist some disadvantages, we should make it clear, not every concept will eliminate discriminations, it still shows that the food does not means food hygiene (a part of food safety), food quality is not equal too, and the food nutrition isn't as equal as food quality.

It all boils down, the concept of food security is easier to pay attention, it should include health, nutrition, food quality and other security features (Figure 1.1), in order to get these features, we should make the food safety supervision to know how to achieve each of the indicators, this gives food safety supervision division of tasks and division of labor challenges.

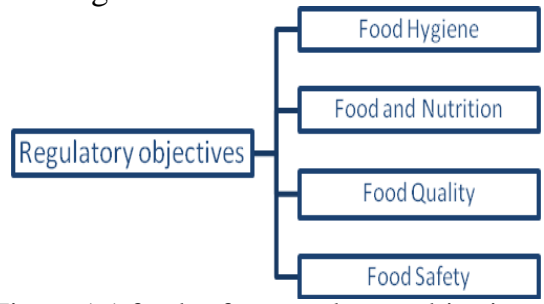

Figure 1.1 food safety regulatory objectives Combine these connotation of the concept, food safety is related to broad the connotation and denotation of all news reports, which including information on food safety, food quality and safety supply news reports; But absolutely safe food and relatively safe level, mainly refers to the level of absolute security is involved in food reported. In the current environment, food safety, this topic can hit the sensitive and fragile nerves of our society members. Thus, the various media reports on food safety issues are often generous layout. In addition, the positive side, which not only meet the public's right to know, but also to fulfill the social responsibility of the media third-party oversight, triggering the public and to promote the sustained attention problems. The network has published 
"Easy dung cannibalism: Chinese Food Security Survey (2004-2011) ". Investigators can easy get the news reports from relevant reports 17268 20042011 , about 10 million words, there is a clear source of screened out, there are victims of the 2107 report, produced a 2849 record, and as each story extracted including the incident involving the type of food, harmful reasons, including a keyword

As shown in Figure 1.2, although food safety incident which the news media coverage of is not increased yearly, can not objectively reflect the worsening food security situation, and thus gradually longitudinal data are not suitable for comparison. In other words, only relying on the number of news media coverage is difficult to launch a video security crisis level, but you can still show the news media for the food safety status of the attention .

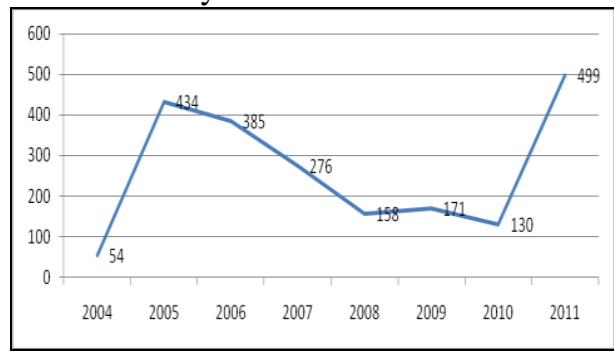

Figure 1.2 2004-2011newsmedia coverage of food safety incidents

Source: According to food safety database collated from throw out the window1

By further consolidation report mentioned problems can still be found in food, food additives and product failure caused by a significant loss of life and property of the people of significant main reasons (Figure 1.3).

\footnotetext{
${ }^{1}$ Throw out the window: the face of food safety crises, you should have the attitude[R $\backslash$ OL].[2013-03-31] http://www.zccw.info.
}

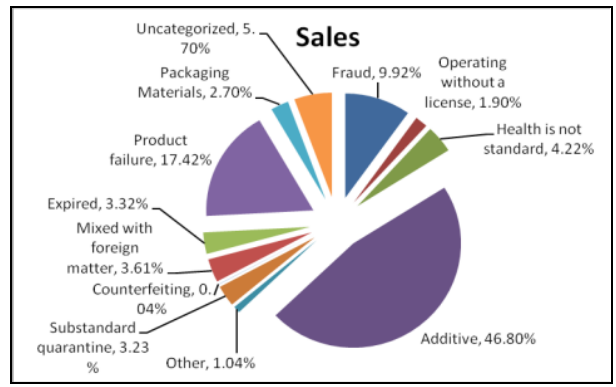

Figure 1.3 2004-2011newsmedia coverage of food safety issues Source: According to food safety data base collated from throw out the window

\section{3. the Problem of Food Safety Report}

Food safety report is the professionalization of the field, both need their support specialized knowledge of reports, also need to understand the relevant knowledge of food disciplines . News media on society a collection of facts , changing the public's political, economic, cultural awareness, the importance of influence can reshape people for political, economic and cultural point of view. Food safety reports, including the content , length , authenticity and other key elements . Through the above food safety database collation and analysis of the contents of reports, which can be found in reports of food safety problems, and make a simple comb, reported distortion caused by external social issues, information from a single source, is not strong professional as well as the energy clear public role positioning.

\subsection{Exaggerated Reports of the Media}

Establish a hot topic, the intention to attract potential " audience ", but exaggerated reports to bring a direct impact on the market order . 201 , on the " leather milk" topic again speculation. "Leather milk" as reported in the news media focus on the topic of "long-term consumption 
can cause cancer ", " leather milk is even more astonishing than the melamine milk ", " carcinogenic leather milk appeared on the market", " leather milk, long-term consumption can cause death "and so eyecatching titles have appeared in public view, in particular, was a lot of major commercial portals reproduced, caused a strong reaction of public opinion. The main purpose is to achieve news sensation, eager to render the food problem , as a witness to the event, the use of the right to occupy public oversight Highland basic qualitative result of the incident , which may exist to the relevant enterprises and industries may cause losses .

\subsection{People's Lack of Knowledge of Food Science}

Prefer to use "toxic", "harmful ", " carcinogenic " and other eye-catching words, the masses do not have the expertise trigger a panic easily . Erroneous news reports focusing on the negative publicity , ignoring the public awareness of food safety, they often recognized by their "victim" role, rather than a true answer to the question of concern, such as food additives in the end without harm, eating how many will have dangerous problems, beef extract additive in news reports, you can call this pork beef extract added, after adding either the taste or appearance and beef are exactly the same, if the long-term use of harmful and can even carcinogenic . For the public, the "cancer " word, is very sensitive, whether it is pathogenic or carcinogenic, public scared by the news media coverage of food safety no confidence.

\section{3. the Governments Keep Silent in Front of the Facts}

Government, as a major source of information channels, the facts before the public in maintaining the "silent ." Most government agencies are the main provider of media coverage, the basic account for more than half of current news coverage ; followed by the food industry, related industries and media itself or the reporter ; Recovery times are health care workers and experts and scholars ; finally did not explain the source or unclear still to a certain percentage. Government agencies or officials, health care workers experts and scholars belong to authoritative sources on the list, but the government in the media sources ranked absolute dominance ; in the field of food safety best qualified medical staff and experts and scholars, vocal fewer opportunities , media information lack of expertise supporting ; higher transparency requirements for sources of information on food safety have not been reported but there are sources confessed or not clear, not only affect the credibility of public access to information confirmed, also reported the loss of professional standards, weakening of social media credibility.

\section{4. the Lack of Social Responsibility and Ethical Awareness}

Mass media is a public instrument, communication resources are scarce users, which determines the media and the public welfare, that is, its society and its members to the maintenance of public interest can not shirk responsibility. If the media dissemination activities just for personal gain , then the spread of society's scarce resources in its possession, the right to enjoy freedom of news media will lose any legal basis. However, in market economy conditions, media organizations with business objectives, it is necessary to profit from operating activities in order to maintain their own survival and development. Media organizations have to face market pressure from two aspects: advertisers and as a consumer audience. Both between the two interrelated and mutually contradictory : on the one hand, the more the audience welcomed the greater circulation or viewership rate is higher, the higher the value of advertising media; the 
other hand, the audience's interests and the interests of advertisers and not the same thing, but in between there is often antagonistic relationship .

\section{5. the Balance of Different Opinions}

Information means the information reported balance and different opinions, attitudes and perspectives balance. This means that the media should any one interest group , any kind of society to express their opinions, and any kind of social benefits vent discontent keep the proper distance, as the expression of multiple interests and emotional catharsis coordinator balancer. "Food safety incidents " direct participants in addition to food producers and food consumers, there are government departments, experts and scholars, they are indirect participants in the event, but also important players, they are independent of the food safety events beyond the direct participants, their views and opinions are more authoritative , more objective , but they also rely on the media attention and the attention of their degree view .

\section{Government Regulation of Food Safety Measures Reported}

Correspondence of media coverage of food safety problems mentioned above, we should improve the food safety information dissemination system to enhance the professionalism of media practitioners to raise public media literacy especially for critical interpretation of media messages and other capabilities, and take effective measure.

\section{1. to Establish a Fair and Objective Reporting Concept of Career}

Journalistic professionalism mainly refers to the journalist career awareness and career awareness around a set of operational requirements of professional journalism It includes the accumulation of expertise , access to expertise and skills training, professional accreditation, highlighting examples of professionalism and professional internal discipline. Journalistic professionalism requires journalists are engaged in related disciplines with expertise, skills, some countries clearly states: in industry reports reporter, engineers must have a qualification certificate; engaged in agriculture reported reporter must have gardeners qualifications ; Sports Reporter athletes to achieve two levels; health reporter to have qualification certificates. This provides us with a useful reference, food safety reports highly professional, we can consider the mechanisms by setting stringent qualification and regular professional training mechanism to enhance the field of media coverage of food safety practitioners professional standards.

\section{2. to Establish a Sound System of Food Safety Information Dissem- ination}

Improving food safety in China reported a variety of ways and means, establish and improve food safety information dissemination system is a key initiatives.

Media often appear in the food safety issue, the first in the government departments involved in the issue of rendering, qualitative , etc., the former lose objectivity and fairness of the media, resulting in the loss of credibility, which is not the media, areas of expertise , easily lead to the government and the public dissatisfaction. Because the government is grappling with the media reported irregularities caused by emotional pressure of public opinion, in the food safety monitoring and information dissemination of not doing enough, lead to poor public satisfaction . Public sources of information and the lack of adequate information generated hunger, the media reported that the lack of ability to identify food safety caused by blind leap of faith , as reported in the media does not regulate food safety and government food safety information 
release is not sufficient harm caused by the final bill

Ideally, the media 's primary role is to act as monitors of the environment and information publishing platform ; government is setting the standard for food safety and food safety watchdogs, with the appropriate qualifications for food safety monitoring and timely release of information on food safety responsibility obligations ; public right to know information on food safety and food safety through the government information disclosure and media coverage of food safety and realization of this right .

\section{3. to Build Public Oversight and Regulation of the Media Channels}

Public media literacy is an important embodiment is to recognize that the media is to engage in " re- constitute operating environment ," the agency, the formation of the real world with the news of the correct understanding of the relationship symbolic world. News symbolic world just for us to learn about the latest developments in the real world as a means, not the only way to get outside information, thereby reducing the public on the activities of the media coverage of food safety unreasonable expectations, but also help enhance public awareness of bad information media dissemination activities resilience

Increasing public media literacy in the premise, explore the establishment of public oversight and regulation of media channels, is to build a public food safety information network effective means. Currently public oversight and regulation of the media channels are the following : first, the personal information feedback. This is one of the most common sources of public regulation. Second, the audience formed groups to groups manner to influence media activities . Compared public personal information feedback, the media in this way will bring greater public pressure, but also more likely to at- tract media attention, and thus more quickly and effectively correct the media reports on food safety unscrupulous behavior . Third, the law demands . Asking the media to the public through legal means to terminate the infringement and compensate for its poor food safety reported losses.

\section{Conclusions}

The Government is still important to regulate food safety body reported . Government food regulatory authorities with the regulatory body for food safety in the course of their duties involve holds food production, distribution, and other aspects of food consumption and import and export key information, and these information in a timely initiative to inform the public, the protection of citizens in the food consumer rights and the right to be informed of the security has an important role.

China's future food security report, the key is to grasp information and establish authoritative information release position. Food safety information release from the food point of view, the relevant government departments should change the passive response caused embarrassment to recognize not only the regulators themselves, but also the authoritative source and information dissemination, and they should respect and protect the public 's right to know. In the food information dissemination system construction, the government reported that the media rights but also to protect food safety, food safety to play the media in information dissemination system in rats. However, we must improve the dissemination of information and dissemination of food regulatory system construction, especially in the media coverage is not standardized enough false reports should be regulated, especially for food additives or other additives are harmful, whether carcinogenic 
and other issues, in its undetermined sex is not to be a clear case reports and how to report on whether you want to be regulated.

\section{References}

[1]A . Akgungor , B . Miran , C. Abay. Consumer Willingness to Pay for Reduced Pesticide Residues in Tomatoes : The Turkish Case $[\mathrm{J}]$. Annual Meeting of the American Agricultural Economics Association, 1999.

[2]Anne Wilcock et al. Consumer Attitudes, Knowledge and Behaviour: A Review of Food Safety Issues[J]. Trends in Food Science and Technology, 2004 (15).

[3] Zhou Baohua, Lu Ye. Audience media information processing capacity[J].News Reporter, 2008(4) [4] Guo Qingguang: Communication Studies tutorial [M].Beijing: China Renmin University Press, 1999. [5] Stanley•Baran, Dennis •Davis. Mass communication theory: basic, Debate and future(third edition) [M]. Cao Shuyue, translation :Beijing : Tsinghua University Press, 2004.

[6]GuoQingguang.Communicationtutorial [M].Beijing: China Renmin University Press. 